\title{
Strategies for optimizing algal biology for enhanced biomass production
}

\section{Amanda N. Barry, Shawn R. Starkenburg and Richard T. Sayre*}

Los Alamos National Laboratory, New Mexico Consortium, Los Alamos, NM, USA

Edited by:

Umakanta Jena, Desert Research

Institute, USA

\section{Reviewed by:}

Alberto Scoma, Ghent University, Belgium

Suyin Gan, The University of Nottingham Malaysia Campus, Malaysia

Chris Fritsen, Desert Research Institute, USA

\section{${ }^{*}$ Correspondence:}

Richard T. Sayre, Los Alamos National Laboratory, New Mexico Consortium, 100 Entrada Dr, Los Alamos, NM

87544, USA

e-mail: rsayre@newmexico

consortium.org

One of the most environmentally sustainable ways to produce high-energy density (oils) feed stocks for the production of liquid transportation fuels is from biomass. Photosynthetic carbon capture combined with biomass combustion (point source) and subsequent carbon capture and sequestration has also been proposed in the intergovernmental panel on climate change report as one of the most effective and economical strategies to remediate atmospheric greenhouse gases. To maximize photosynthetic carbon capture efficiency and energy-return-on-investment, we must develop biomass production systems that achieve the greatest yields with the lowest inputs. Numerous studies have demonstrated that microalgae have among the greatest potentials for biomass production. This is in part due to the fact that all alga cells are photoautotrophic, they have active carbon concentrating mechanisms to increase photosynthetic productivity, and all the biomass is harvestable unlike plants. All photosynthetic organisms, however, convert only a fraction of the solar energy they capture into chemical energy (reduced carbon or biomass). To increase aerial carbon capture rates and biomass productivity, it will be necessary to identify the most robust algal strains and increase their biomass production efficiency often by genetic manipulation. We review recent large-scale efforts to identify the best biomass producing strains and metabolic engineering strategies to improve aerial productivity. These strategies include optimization of photosynthetic light-harvesting antenna size to increase energy capture and conversion efficiency and the potential development of advanced molecular breeding techniques. To date, these strategies have resulted in up to twofold increases in biomass productivity.

Keywords: algae, biomass, biofuel, photosynthesis, lipid, carbohydrate, chlorella sorokiniana, chlamydomonas reinhardtii

\section{INTRODUCTION}

Over the past 5 years, tremendous progress has been made in the technical and economic development of algal biofuel production systems (Chisti, 2008; Mata et al., 2010; Campbell et al., 2011; National Research Council, 2012; NAABB Final Report, 2014). In 2010, the "state of the art" technologies used to produce biodiesel from algae included paddle-wheel driven pond cultivation, centrifugation-based harvesting, biomass drying, and transesterification and resulted in fuel costs of over \$100/gge (National Research Council, 2012). Recent advances in algal biofuel production technologies have rapidly moved the industry from an economic uncertainty to an economic feasibility (Chisti, 2008; Williams and Laurens, 2010; Campbell et al., 2011; Richardson et al., 2014; NAABB Final Report, 2014). For example, the recent close-out report for the National Alliance of Advanced Biofuels and Bioproducts (NAABB) describes an integrated pathway from algal biomass production to fuel conversion that approaches an estimated cost of $\$ 8.00 /$ gge while achieving nearly $90 \%$ recovery of all carbon in biomass as fuel (NAABB Final Report, 2014). An important part of the cost reduction of producing algal biofuels was the use of hydrothermal liquefaction (HTL) (elevated temperature, $250-350^{\circ} \mathrm{C}$, and pressure, $10-20 \mathrm{MPa}$, treatment) of wet biomass to produce biocrude coupled with catalytic hydrogen gasification of the water soluble fraction remaining from HTL to produce methane (Jena et al., 2011 a,b; NAABB Final Report, 2014). Algal biocrude was successfully converted into diesel, gasoline, and/or aviation fuel with the appropriate catalysts and treatments (NAABB Final Report, 2014). Significantly, NAABB supported life cycle analyses (LCA) also identified the major constraints limiting the production of fuels from algae at economic parity with petroleum. The major constraints limiting economic parity of algal biofuels with petroleum include (1) the limited production of algal biomass per unit land area, and (2) the energy and economic costs associated with scalable algae harvesting (National Research Council, 2012; NAABB Final Report, 2014). For algal biofuels to achieve economic parity with petroleum, algal biomass yields will need to be increased approximately threefold from 12 to $>30 \mathrm{gdw} / \mathrm{m}^{2} /$ day on a sustained basis. In addition, the energy-return-on-investment (EROI) for harvesting algae from ponds ideally would need to be $>20$, i.e., no more than $5 \%$ of the energy content of the algae is used for harvest (NAABB Final Report, 2014).

Focusing only on commodity scale production of fuels from algae is, however, not the only approach for achieving economic parity with petroleum. One approach for reducing the costs of producing fuels from algae is the co-production of high-value products along with the biofuel feedstock (National Research 
Council, 2012; NAABB Final Report, 2014). In addition, a new potential economic driver for the reduction in algal biofuel costs is emerging; i.e., the potential for carbon capture and sequestration. The recent Intergovernmental Panel for Climate Change (IPCC) report has identified biological energy production coupled with carbon capture and sequestration (BECCS) as the most technological and economically viable solutions for removing carbon from the atmosphere to mitigate the impact of greenhouse gases on Climate Change (2014). Briefly, carbon removed from the atmosphere through photosynthesis is converted into biofuel. Energy generated from biofuel combustion at a point source generates income while also reducing demand for fossil fuels. The concentrated $\mathrm{CO}_{2}$ released from biofuel combustion at the point source is subsequently captured and sequestered before entering the atmosphere. Coupling bioenergy production with carbon sequestration (BECCS), including subterranean $\mathrm{CO}_{2}$ injection or biochar carbon sequestration, results in a net removal of carbon from the atmosphere (Climate Change, 2014). If enacted, tax credits and/or carbon credit policies could provide cost reductions for producing bioenergy from algae coupled with carbon capture and sequestration. In the following review, we consider various strategies for increasing overall algal bioenergy production yields while reducing costs and enhancing carbon capture. These strategies include selection of the most robust and greatest yielding algal biomass strains coupled with genetic improvements to increase photosynthetic efficiency.

\section{RECENT PROGRESS IN ENHANCING MICROALGAL BIOFUEL FEED STOCK PRODUCTION}

Recently, it has been recognized that the EROI for downstream algal biomass conversion to fuel technologies is less constrained by the biochemical composition (oil versus carbohydrate and protein) of the biomass than previously thought (Sayre, 2010; Subramanian et al., 2013). To date, much of the focus on improving algal biofuel production yields has focused on increasing lipid content or the energy density of the biomass, often at the expense of total biomass yield (Huerlimann et al., 2010; Sharma et al., 2012; Subramanian et al., 2013). Since total energy yield is the product of both the biomass energy density and the total biomass yield, the most efficient means to increase overall biomass to fuel EROI is to determine the ideal balance between biomass energy density (lipid, carbohydrate, and protein composition) and biomass yield that gives the greatest total energy yield. In addition, we must also consider the optimal algal biochemical composition that yields the greatest EROI during biomass conversion to fuel. Recently, analyses of the thermodynamics of solar energy conversion by algae into combustible energy storage products (oil and carbohydrate) indicate that carbohydrate production is thermodynamically more efficient than oil production (Subramanian et al., 2013). The overall EROI from photosynthetically captured red photons to heat of combustion is $59 \%$ for triacylglycerol (TAG, $\mathrm{C}_{55} \mathrm{H}_{98} \mathrm{O}_{6}$ ) and $64 \%$ for starch $\left(\mathrm{C}_{6} \mathrm{H}_{12} \mathrm{O}_{6}\right)$ on a per carbon basis (Table $\mathrm{S} 1$ in Supplementary Material). Furthermore, carbohydrate production may be kinetically less constrained than lipid production and starch may serve as a reduced carbon source for lipid production (Subramanian et al., 2013). Relevant to this hypothesis, recent analyses of the EROI for algal biomass conversion into biocrude by HTL indicates that the biomass to fuel conversion EROI is similar for algal biomass feed stocks having a broad range of carbohydrate to oil ratios (Campbell et al., 2011). The EROI for biocrude production using Nannochloropsis (32\% oil, 57\% protein, $8 \%$ carbohydrate) was $66 \%$, while for Porphyridium (8\% oil, $43 \%$ protein, $40 \%$ carbohydrate), which has a fourfold lower oil content and a fivefold higher carbohydrate content, the EROI for biocrude production was $52 \%$ (Table S2 in Supplementary Material). Thus, HTL treatment of algal biomass generates a biocrude product having similar EROIs from feed stocks having a broad range of lipid content. To optimize total bioenergy yield from sun to fuel, we need to select, breed, or design algae that are not only the most efficient at energy capture, conversion, and storage, but which have the optimal carbohydrate: lipid ratios that will give both the greatest total energy yield in production and the greatest EROI for biomass to fuel conversion.

\section{EMERGING BIOENERGY PRODUCTION STRAINS}

Whereas Chlamydomonas has many features that make it an ideal model organism for evaluating various metabolic engineering and breeding strategies to improve crop yield and robustness, it has limited potential as a production strain due primarily to limitations in the maximal cell number or biomass density achieved at saturating or stationary phase cultures (NAABB Final Report, 2014). The NAABB consortium conducted an extensive bioprospecting effort to identify wild algal isolates that had the highest biomass yield and energy densities (Branyikova et al., 2011; Li et al., 2013; NAABB Final Report, 2014). One of the most productive species identified by two independent groups within the NAABB consortium was Chlorella sorokiniana. C. sorokiniana has an optimal growth temperature of $37^{\circ} \mathrm{C}$, and is able to grow heterotropically on a variety of sugars that enhance oil accumulation. Under N-starvation, C. sorokiniana was shown to accumulate neutral lipids, accumulate oil droplets, and exhibited an increased oxidative stress response with damage to photosystem II (PSII) (Zhang et al., 2013). Growth in an optimized mixoand heterotrophic bioreactor supplemented with glucose enabled C. sorokiniana UTEX 1230 to accumulate $30-40 \%$ of its cell mass as lipids (Rosenberg et al., 2014). Furthermore, while growing in the absence of nitrogen (following pre-growth with ammonia at dry weight production rates equivalent to growth in the presence of ammonia), the energy content of the algae increased by nearly $50 \%$ on a dry weight basis (Sangeeta Negi, personal communication). This increase in energy content was associated with elevated TAG levels. The ability to grow at unimpeded rates while increasing energy density in the absence of nitrogen for extended periods of time is not commonly observed in many algal species, which typically have reduced growth rates as they become nitrogen starved of the course of several weeks. Pre-loading production strains with sufficient nutrients to produce high biomass and lipid yields in the absence of macro-nutrients, or using so-called nutrientpulse technology, is potentially one way of controlling weedy or competing algal contaminants in production systems.

Currently, we are improving and annotating the genomes of three independent C. sorokiniana isolates (Table 1; NAABB Final Report, 2014). Two of these genomes, strain "1412" and UTEX 1230, were drafted by the NAABB Consortium (NAABB Final Report, 2014) and most recently, a genome assembly and 
Table 1 | Genome statistics for strains of $\boldsymbol{C}$. sorokiniana (NAABB Final Report, 2014).

\begin{tabular}{llll}
\hline Strain & $\mathbf{1 4 1 2}$ & UTEX 1230 & $\mathbf{1 2 2 8}$ \\
\hline Quality & Improved draft & Improved draft & Improved draft \\
Platform(s) & Illumina & Illumina + Pacbio & Pacbio + Opgen \\
Assembly size & $59.3 \mathrm{MB}$ & $60 \mathrm{MB}$ & $61 \mathrm{MB}$ \\
Contigs & 5949 & 746 & 66 \\
Contig N50 & $19.5 \mathrm{~kb}$ & $812 \mathrm{~kb}$ & $2.35 \mathrm{MB}$ \\
Max contig size & $122 \mathrm{~kb}$ & $2.6 \mathrm{MB}$ & $4.56 \mathrm{MB}$ \\
Chromosomes $^{\text {N.D. }}$ & N.D. & N.D. & 12 \\
\% Unique $^{\text {a }}$ & $93.9 \%$ & $95.8 \%$ & N.A.
\end{tabular}

${ }^{a}$ Indicates the percentage of unique nucleotide sequence $(<90 \%$ identity) between strains of $C$. sorokiniana. The unique sequence indicated for $C$. sorokiniana strain UTEX 1230 was calculated from a comparison to C. sorokiniana strain 1228. The percentage of unique sequence indicated for C. sorokiniana strain 1412 was calculated from a comparison to both strain 1230 and 1228. N.D., not determined; N.A., not applicable.

annotation project was initiated for a new strain; C. sorokiniana 1228. Preliminary analysis of the improved drafts from these three strains indicates that all C. sorokiniana species have approximate genome sizes of $60 \mathrm{MB}$ and that the dominant generation is diploid. Despite the similarity in genome size, only $4-6 \%$ of each genome is highly conserved (4-6 MB of each genome share $>90 \%$ nucleotide identity), which suggests that each strain has unique genotypic/phenotypic properties that can be combined to further improve the performance in a production environment (Table 1).

With respect to strain improvement, we have developed nuclear transformation vectors for $C$. sorokiniana based on the use of $C$. sorokiniana gene promoters identical to those identified to be optimal for gene expression in Chlamydomonas (Kumar et al., 2013). PCR positive transformants of codon-optimized foreign genes have also been identified based on paromomycin selection. In the future, breeding algae for improved performance will likely be a part of the repertoire for crop improvement. Using advanced molecular assisted breeding techniques, gene tagging and activation strategies, and mutagenesis approaches to breed for strains with enhanced yield and range of environmental performance may substantially increase crop yields. The major challenge for many diploid algae has been the identification of conditions that induce meiosis, gametogenesis, and mating. Recently, it has been observed that diploid Chlorella species have genes essential for meiosis as well as flagellar genes, required for mating (Blanc et al., 2010). As indicated above, we have observed substantial genetic variation in independent isolates of $C$. sorokiniana suggesting that there is considerable opportunity for crop improvement through molecular assisted breeding and genome editing technologies.

\section{INCREASING SOLAR ENERGY CAPTURE AND CONVERSION EFFICIENCY FOR ENHANCED FUEL PRODUCTION}

The earliest event in photosynthesis is the capture of photons by the light-harvesting antenna protein-pigment complexes of the chloroplast thylakoid membranes (Zhu et al., 2010; Subramanian et al., 2013). In chlorophytic (green) algae, the majority (>70\%) of chlorophyll (Chl) is associated with the light-harvesting antenna complexes (Perrine et al., 2012). The antenna complexes capture and transfer energy to the reaction center complexes (PS I and II) where charge separation occurs. Significantly, energy migration within the light-harvesting antenna complex is very efficient occurring by quantum coherence processes (Subramanian et al., 2013). Highly efficient light capture by large antenna, even though wasteful, confers a selective advantage in mixed species populations by limiting light availability for competing species as well as facilitating light capture at low light flux densities deep in the canopy or water column (Blankenship et al., 2011). However, the very large apparent optical cross sections of light-harvesting complexes trap substantially more photons than accommodated by the photosynthetic electron transfer apparatus (Perrine et al., 2012). Indeed, at full sunlight intensities the rate of photon capture is 10 -fold faster than the rate-limiting step $(1-10 \mathrm{~ms})$ in electron transfer associated with plastohydroquinol oxidation by the cytochrome b6f complex (Perrine et al., 2012). As a result, $80 \%$ of the trapped energy is dissipated as heat or Chl fluorescence at full sunlight intensities [2000 $\mu \mathrm{mol}$ photosynthetically active (400-700 nm) photons $/ \mathrm{m}^{2} / \mathrm{s}$ (Mussgnug et al., 2005; Perrine et al., 2012].

Photosynthetic carbon dioxide fixation is challenged by various constraints as well including: photorespiratory energy and $\mathrm{C}$ losses from RuBisCO oxygenase activity, limiting abundance of critical metabolic enzymes, and metabolic feedback from inefficiencies in C flux from source to sinks (Giordano et al., 2005; Spalding, 2009; Zhu et al., 2010; Branyikova et al., 2011; Johnson and Alric, 2013). Overall, the maximum thermodynamic efficiency for photosynthesis using red photons to produce carbohydrate is 25-30\% (Subramanian et al., 2013). If the entire solar spectrum is factored into the energy efficiency calculations then the maximum solar-to-biomass conversion efficiency only approaches $11 \%$ (Giordano et al., 2005; Zhu et al., 2010; Subramanian et al., 2013; Torzillo et al., 2014). In reality, the thermodynamic efficiency for harvestable biomass production is typically $<3 \%$, due in part to kinetic constraints in photosynthesis, respiratory losses, and negative feedback regulation by the sink (Zhu et al., 2010; Johnson and Alric, 2013; Subramanian et al., 2013).

Substantial improvements in photosynthesis and biomass yield have been achieved in algae. The greatest yield improvements, to date, have been achieved by optimizing the size of the lightharvesting antenna complex to reduce inefficiencies in energy conversion (Mussgnug et al., 2005; Perrine et al., 2012). Engineering "intermediate" antenna sizes in Chlamydomonas reinhardtii improved photosynthetic rates and biomass yields on the order of $10-30 \%$ in laboratory cultures (Polle et al., 2001; Mussgnug et al., 2005; Melis, 2009; Perrine et al., 2012). To achieve an intermediate antenna size, the synthesis of $\mathrm{Chl} \mathrm{b}$, which is bound only to the peripheral light-harvesting antenna complex proteins, was reduced by inhibiting the synthesis of Chl a oxygenase, the enzyme that converts $\mathrm{Chl}$ a into $\mathrm{Chl} \mathrm{b}$, using RNAi technology (Perrine et al., 2012). Most recently, this approach to reduce antenna size, and thus increase biomass productivity, was performed in C. sorokiniana, where UV mutagenesis was utilized to isolate truncated antenna mutants (Cazzaniga et al., 2014). PSII antenna reduction $(48 \%$ of LHCII protein content compared to 
wild-type) resulted in a $32 \%$ increased mean biomass productivity over wild-type strains when grown in photobioreactors.

\section{CONCLUDING REMARKS}

Overall, there continues to be a need to identify and or engineer the best and most robust algal strains to produce the greatest amount of biomass. Additional traits that are desirable for sustainable algal biomass production include; heat tolerance (to reduce the need for evaporative cooling and to seal ponds to reduce water demand), inducible self-flocculation (to reduce harvesting costs), herbivore resistance, and traits that reduce competition by unwanted algal contaminants. Furthermore, it is understood that different algal species will be optimal in different environments and produce greater biomass at different seasons of the year. Rotating production strains (crops) during the year to optimize yields is one strategy successfully used in agriculture to optimize yield. For algal crop improvement to approach the historical yield increases achieved in crop plants, a combination of using the best producing species, development of diverse breeding populations, and application of genome editing and transgenic approaches will need to be developed. There is great potential for yield improvement in this largely untapped resource of genetic and phenotypic diversity.

\section{SUPPLEMENTARY MATERIAL}

The Supplementary Material for this article can be found online at http://www.frontiersin.org/Journal/10.3389/fenrg.2015.00001/ abstract

\section{REFERENCES}

Blanc, G., Duncan, G., Agarkova, I., Borodovsky, M., Gurnon, J., Kuo, A., et al. (2010). The Chlorella variabilis NC64A genome reveals adaptation to photosymbiosis, coevolution with viruses, and cryptic sex. Plant Cell 22, 2943-2955. doi:10.1105/tpc.110.076406

Blankenship, R. E., Tiede, D. M., Barber, J., Brudvig, G. W., Fleming, G., Ghirardi, M., et al. (2011). What is the solar energy conversion efficiency of natural photosynthesis compared to photovoltaic cells? Science 332, 805-809. doi:10.1126/science. 1200165

Branyikova, I., Marsalkova, B., Doucha, J., Branyik, T., Bisova, K., Zachleder, V., et al. (2011). Microalgae - novel highly efficient starch producers. Biotechnol. Bioeng. 108, 766-776. doi:10.1002/bit.23016

Campbell, P. K., Beer, T., and Batten, D. (2011). Life cycle assessment of biodiesel production from microalgae in ponds. Bioresour. Technol. 102, 50-56. doi:10. 1016/j.biortech.2010.06.048

Cazzaniga, S., Dall'Osto, L., Szaub, J., Scibilia, L., Ballottari, M., Purton, S., et al. (2014). Domestication of the green alga Chlorella sorokiniana: reduction of antenna size improves light-use efficiency in a photobioreactor. Biotechnol. Biofuels 7, 157-170. doi:10.1186/s13068-014-0157-z

Chisti, Y. (2008). Biodiesel from microalgae beats bioethanol. Trends Biotechnol. 26, 126-131. doi:10.1016/j.tibtech.2007.12.002

Climate Change. (2014). Mitigation of Climate Change. Intergovernmental Panel on Climate Change. Available at: http://www.ipcc.ch/

Giordano, M., Beardall, J., and Raven, J. A. (2005). CO2 concentrating mechanisms in algae: mechanisms, environmental modulation, and evolution. Annu. Rev. Plant Biol. 56, 99-131. doi:10.1146/annurev.arplant.56.032604.144052

Huerlimann, R., de Nys, R., and Heimann, K. (2010). Growth, lipid content, productivity, and fatty acid composition of tropical microalgae for scale-up production. Biotechnol. Bioeng. 107, 245-257. doi:10.1002/bit.22809

Jena, U., Vaidyanathan, N., Chinnasamy, S., and Das, K. C. (2011a). Evaluation of microalgae cultivation using recovered aqueous co-product from thermoliquefaction of algal biomass. Bioresour. Technol. 102, 3380-3387. doi:10.1016/j. biortech.2010.09.111

Jena, U., Das, K. C., and Kastner, J. R. (2011b). Effect of operating conditions of thetmoliquefaction on biocrude production from Spirulina platensis. Bioresour. Technol. 102, 6221-6229. doi:10.1016/j.biortech.2011.02.057
Johnson, X., and Alric, J. (2013). Central carbon metabolism and electron transport in Chlamydomonas reinhardtii: metabolic constraints for carbon partitioning between oil and starch. Eukaryotic Cell 12, 776-793. doi:10.1128/ EC.00318-12

Kumar, A., Falcao, V. R., and Sayre, R. T. (2013). Evaluating nuclear transgene expression systems in Chlamydomonas reinhardtii. Algal Res. 2, 321-332. doi:10.1016/j.algal.2013.09.002

Li, T., Zheng, Y., Yu, L., and Chen, S. (2013). High productivity cultivation of a heat-resistant microalgae, Chlorella sorokiniana for biofuel production. Bioresour. Technol. 131, 60-67. doi:10.1016/j.biortech.2012.11.121

Mata, T. M., Martins, A. A., and Caetano, N. S. (2010). Microalgae for biodiesel production and other applications: a review. Renew. Sustain Energy Rev. 14, 217-232. doi:10.1016/j.rser.2009.07.020

Melis, A. (2009). Solar energy conversion efficiencies in photosynthesis: minimizing the chlorophyll antennae to maximize efficiency. Plant Sci. 177, 272-280. doi:10.1016/j.plantsci.2009.06.005

Mussgnug, J. H., Wobbe, L., Elles, I., Claus, C., Hamilton, M., Fink, A., et al. (2005). NAB1 is an RNA binding protein involved in the light-regulated differential expression of the light-harvesting antenna of Chlamydomonas reinhardtii. Plant Cell 17, 3409-3421. doi:10.1105/tpc.105.035774

NAABB Final Report. (2014). National Alliance for Advanced Biofuels and Bioproducts Synopsis (NAABB) Final Report. Available at: http://energy.gov/eere/ bioenergy/downloads/national-alliance-advanced-biofuels-and-bioproductssynopsis-naabb-final

National Research Council. (2012). Sustainable Development of Algal Biofuels. Washington, DC: The National Academies Press.

Perrine, Z., Negi, S., and Sayre, R. T. (2012). Optimization of photosynthetic light energy utilization by microalgae. Algal Res. 1, 134-142. doi:10.1016/j.algal.2012. 07.002

Polle, J., Kanakagiri, S., Benemann, J. R., and Melis, A. (2001). "Maximizing photosynthetic efficiencies and hydrogen production by microalgal cultures," in Biohydrogen II: An Approach to Environmentally Acceptable Technology, eds J. Miyake, T. Matsunanga, and A. San Pietro (Oxford: Pergamon Press), 111-130.

Richardson, J. W., Johnson, M. D., Zhang, X., Zemke, P., Chen, W., and Hu, Q. (2014). A financial assessment of two alternative cultivation systems and their contributions to algae biofuel economic viability. Algal Res. 4, 96-104. doi:10.1016/j.algal.2013.12.003

Rosenberg, J. N., Kobayashi, N., Barnes, A., Noel, E. A., Betenbaugh, M. J., and Oyler, G. A. (2014). Comparative analyses of three chlorella species in response to light and sugar reveal distinctive lipid accumulation patterns in the microalga C. sorokiniana. PLoS ONE 9:e92460. doi:10.1371/journal.pone.0092460

Sayre, R. T. (2010). Microalgal biofuels; carbon capture and sequestration. Bioscience 60, 722-727. doi:10.1525/bio.2010.60.9.9

Sharma, K. K., Schuhmann, H., and Schenk, P. M. (2012). High lipid induction in microalgae for biodiesel production. Energies 5, 1532-1553. doi:10.3390/ en5051532

Spalding, M. H. (2009). $\mathrm{CO}_{2}$-Concentrating Mechanism and Carbon Assimilation. Oxford: Academic Press.

Subramanian, S., Barry, A. N., Pieris, S., and Sayre, R. T. (2013). Comparative energetics and kinetics of autotrophic lipid and starch metabolism in chlorophytic microalgae: implications for biomass and biofuel production. Biotechnol. Biofuels 6, 150-162. doi:10.1186/1754-6834-6-150

Torzillo, G., Scoma, A., Faraloni, C., and Giannelli, L. (2014). Advances in the biotechnology of hydrogen production with the microalga Chlamydomonas reinhardtii. Crit. Rev. Biotechnol. doi:10.3109/07388551.2014.900734

Williams, P. J. B., and Laurens, L. M. L. (2010). Microalgae as biodiesel \& biomass feedstocks: review \& analysis of the biochemistry, energetics \& economics. Energy Environ. Sci. 3, 554-590. doi:10.1039/b924978h

Zhang, Y. M., Chen, H., He, C. L., and Wang, Q. (2013). Nitrogen starvation induced oxidative stress in an oil-producing green alga Chlorella sorokiniana C3. PLoS ONE 8:e69225. doi:10.1371/journal.pone.0069225

Zhu, X. G., Long, S. P., and Ort, D. R. (2010). Improving photosynthetic efficiency for greater yield. Annu. Rev. Plant Biol. 61, 235-261. doi:10.1146/annurev-arplant042809-112206

Conflict of Interest Statement: The authors declare that the research was conducted in the absence of any commercial or financial relationships that could be construed as a potential conflict of interest. 
Received: 29 September 2014; accepted: 13 January 2015; published online: 02 February 2015.

Citation: Barry AN, Starkenburg SR and Sayre RT (2015) Strategies for optimizing algal biology for enhanced biomass production. Front. Energy Res. 3:1. doi: 10.3389/fenrg.2015.00001

This article was submitted to Bioenergy and Biofuels, a section of the journal Frontiers in Energy Research.
Copyright (C) 2015 Barry, Starkenburg and Sayre. This is an open-access article distributed under the terms of the Creative Commons Attribution License (CC $B Y)$. The use, distribution or reproduction in other forums is permitted, provided the original author(s) or licensor are credited and that the original publication in this journal is cited, in accordance with accepted academic practice. No use, distribution or reproduction is permitted which does not comply with these terms. 